\title{
Electrocardiographic changes in patients with acute brain injury
}

A 19-year-old man (patient 01) was admitted into the intensive care unit (ICU), in a coma, after surgical drainage of a traumatic subdural hematoma. Another patient (02), 40 years old, was admitted into the ICU for intraparenchymal cerebral hemorrhage (Fisher scale $=4$; Glasgow coma scale $=4$ ). Both patients had changes in continuous cardiac monitoring, which suggested ST-segment elevation. For diagnostic clarification, electrocardiograms (figure) were performed, which revealed Osborn waves (arrows), sinus bradycardia, longer intervals of QRS and corrected QT (QTc). Heated intravenous solution infusion and thermal blankets were used in an attempt to reverse hypothermia. However, both patients remained hypothermic and died in a few hours.

The Osborn wave, also called J-wave, was first described in 1953 as "a secondary wave that follows the $\mathrm{S}$ wave so closely that it seems to be part of the QRS complex"1. Hypothermia syndrome is predominantly described in Brazil in near-drowning cases; however, it is important to remember that acute brain injuries may evolve from it. In fact, the relationship between hypothermia and cerebral injury is controversial. The benefits of therapeutic hypothermia for neuronal protection after acute injury has been previously demonstrated in animal models, but have yet to be reproduced in humans ${ }^{2}$. More recently, the negative impact of spontaneous hypothermia in patients with acute brain injury began to be recognized. In these cases, the spontaneous fall in core temperature below $35^{\circ} \mathrm{C}$ increased mortality by $50 \%$. Despite the absence of studies correlating Osborn waves and a worse prognosis for patients with hypothermia, QT interval prolongation is a known risk factor for cerebral vasospasm after subarachnoid hemorrhage ${ }^{3}$. Thus, professionals involved in the treatment of patients with acute brain injury should be able to recognize electrocardiographic changes that may indicate hypothermia and worse prognosis in these patients. 


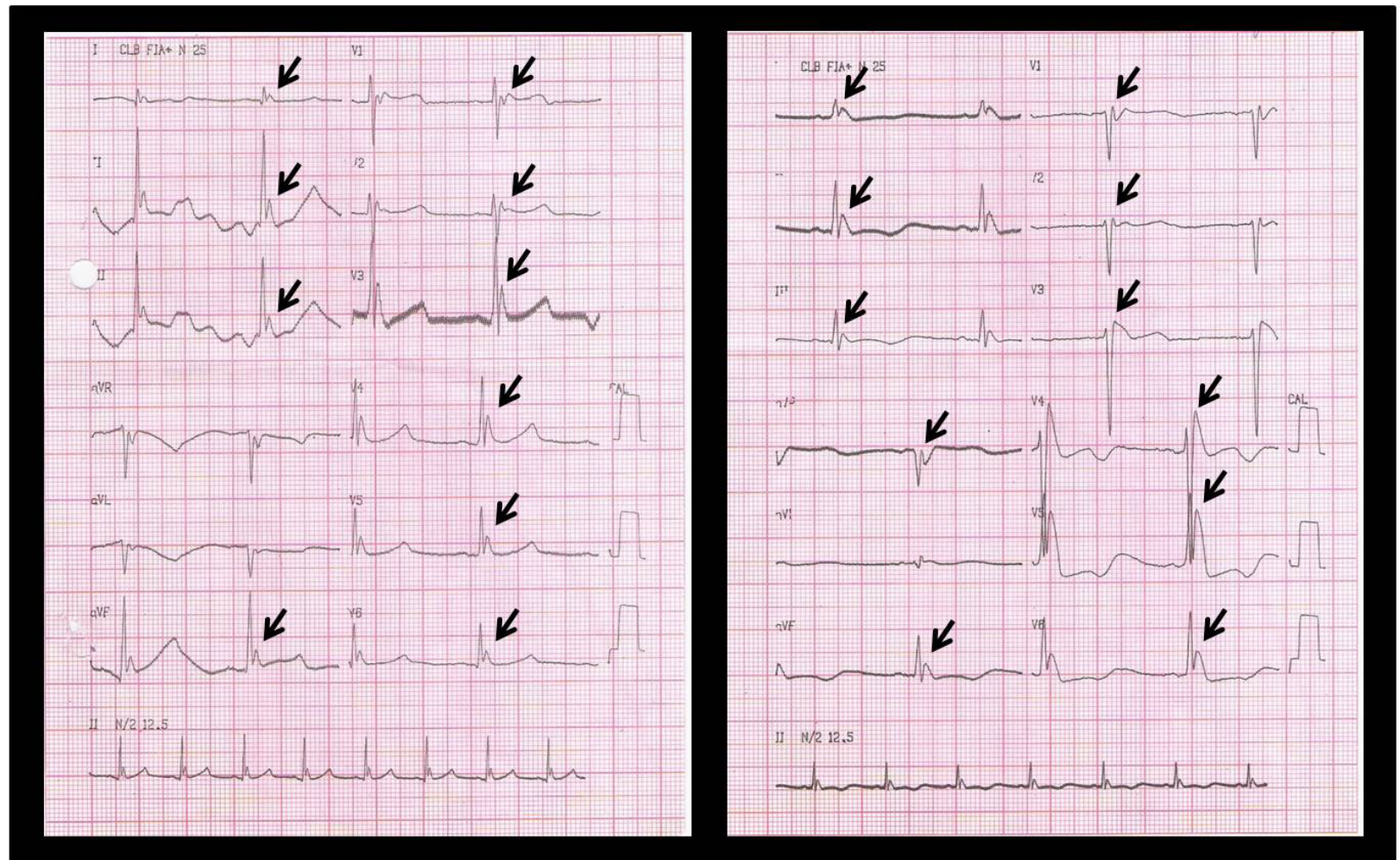

\begin{tabular}{l|l|l} 
& Patient 1 & Patient 2 \\
\hline Temperature $\left({ }^{\circ} \mathrm{C}\right)$ & $<32$ & $<32$ \\
\hline Heart rate $(\mathrm{bpm})$ & 56 & 46 \\
\hline QRS Interval $(\mathrm{ms})$ & 160 & 220 \\
\hline QTc Interval $(\mathrm{ms})$ & 502 & 600 \\
\hline
\end{tabular}

PALAVRAS-CHAVE: Lesões encefálicas. Doença aguda. Eletrocardiografia.

\section{REFERENCES}

1. Osborn J]. Experimental hypothermia; respiratory and blood pH changes in relation to cardiac function. Am J Physiol. 1953;175(3):389-98.

2. Clifton GL, Miller ER, Choi SC, Levin HS, McCauley S, Smith KR Ir, et al. Lack of effect of induction of hypothermia after acute brain injury.
N Engl | Med. 2001;344(8):556-63.

3. Ibrahim GM, MacDonald RL. Electrocardiographic changes predict angiographic vasospasm after aneurysmal subarachnoid hemorrhage. Stroke. 2012;43(8):2102-7. 